Polish Journal of Microbiology

2012, Vol. 61, No 2, 81-93

MINIREVIEW

\title{
Q Fever at the Turn of the Century
}

\author{
TOMASZ CHMIELEWSKI* and STANISEAWA TYLEWSKA-WIERZBANOWSKA
}

Laboratory of Rickettsiae, Chlamydiae and Enzotic Spirochetes,

National Institute of Public Health - National Institute of Hygiene, Warsaw

Received 10 October 2011, accepted 5 May 2012

\begin{abstract}
Q fever is an infectious zoonotic disease characterized by sudden fever, headache, and atypical pneumonia, caused by Coxiella burnetii - an obligatory intracellular parasite. Based on phylogenetic analysis of the genes sequences, the classification was changed and C. burnetii species was included to the gamma subgroup of the proteobacteria, Legionellales order and Coxiellaceae family. This analysis showed more than 99\% sequence similarity of 16SrRNA gene among the strains isolated in different regions of the world. Q fever is a widespread in the world zoonosis. Its main reservoir in the rural environment are farm animals: cows, sheep, goats, and urban pets such as dogs, cats, rabbits. In acute infection these bacteria are detected in various internal organs such as lungs, liver, spleen, and in excretion in urine, faeces and milk. During childbirth, they occur in large number in the amniotic fluid and placenta. Recently, it has been found that free-living amoeba Acanthamoeba castellani may also be a reservoir of the pathogen. The intra-amoebal location of $C$. burnetii cells was observed.
\end{abstract}

Ke y words: Coxiella burnetii, Q fever, zoonosis

\section{Introduction}

Q fever is an infectious zoonotic disease characterized by sudden fever, headache, and atypical pneumonia, caused by Coxiella burnetii - an obligatory intracellular parasite. For the first time the disease was recognized in 1935 and described in 1937 by Derrick, when he studied an unknown disease outbreak among abattoir workers in Brisbane,Australia (Derrick, 1937). The predominant symptom was a fever of unknown origin (called "query"). Isolation of etiologic agent attempts failed, but transfer of infection to guinea pig was successful. For this reason, it was thought that the disease was caused by unknown viruses (Burnet and Freeman, 1937). Two years after the outbreak, bacterial etiology was discovered by Burnet and Freeman (Burnet and Freeman, 1938). They injected guinea pigs with blood and urine of Derrick's patients and observed the presence of intracellular Gram-negative organisms morphologically similar to Rickettsia sp. in stained spleen cells preparations. In 1938, Cox developed a method of culture in chicken embryos, which allowed to isolate the bacterial strains and to investigate them (Cox, 1941).

\section{Classification of Coxiella burnetii}

Initially the microorganism was named Rickettsia burnetii, because of the characteristic features of all Rickettsia species. They are small Gram-negative coccoid rods. They are absolute intracellular parasites and can be cultivated in laboratory animals, chicken embryos or cell lines. In vertebrates infection involves reticulo-endothelial, vascular endothelial cells or erythrocytes. C. burnetii bacteria were found in the gut and haemolymph of ticks, suggesting that they are a natural vector as for other rickettsiae (Rehacek and Tarasevich, 1988). Currently, ticks are considered to be a reservoir in the environment.

In 1948 Philip proposed to create a new genus of Coxiella and classify the bacteria as a new species Coxiella burnetii (the name in honour of the discoverers - Cox and Burnet).

Until the 90s, this organism had been classified as alpha subgroup of proteobacteria, order Rickettsiales, and together with the genera Rickettsia and Rochalimea as Rickettsiaceae family. At the end of the nineties, a small subunit of rRNA was sequenced and determined for representative strains of six species of

\footnotetext{
* Corresponding author: T. Chmielewski, Laboratory of Rickettsiae, Chlamydiae and Enzotic Spirochetes, National Institute of Public Health - National Institute of Hygiene; Chocimska 24, 00-791 Warsaw, Poland; e-mail: tchmielewski@pzh.gov.pl
} 
the family Rickettsiaceae: Rickettsia rickettsii (ATCC VR 891), Rickettsia prowazekii (strain Breinl), Rickettsia typhi (strain Wilmington), Coxiella burnetii (strain Q177), Ehrlichia risticii (ATCC VR 986), and Wolbachia persica (ATCC VR 331). The relationships among these sequences and those of other eubacteria (about 100 sequences of purple bacteria group) show that three representatives of the genus Rickettsia form a tight monophyletic cluster within the alpha subdivision of the purple bacteria. E. risticii also belongs to the alpha subdivision and shows a distant relationship to the genus Rickettsia. Sequencing DNA fragment of rRNA gene revealed that C. burnetii and W. persica are members of the gamma subdivision and they show a specific, although distant relationship to the genus Legionella (Weisburg et al., 1989). This phylogenetic study was based on one C. burnetii strain only. In the next study, fragments of 16SrRNA gene (about 95\%) from six strains were sequenced. Five of these strains were isolated from humans (strains: Q212, MEI1, ME5, MAC12, ME6) and one from tick (Nine Mile). They represented different pathogenic characteristic and geographic origin (USA, Canada, France). Based on phylogenetic analysis of these genes sequences, the classification was changed and C. burnetii species was included to the gamma subgroup of the proteobacteria, Legionellales order and Coxiellaceae family. This analysis showed more than $99 \%$ sequence similarity of 16SrRNA gene among the strains isolated in different regions of the world. The result of the study has shown the presence of one species only within the genus Coxiella (Stein et al. 1993).

\section{Biology of Coxiella burnetii}

\section{Morphology}

C. burnetii is a pleomorphic, Gram-negative small rod with a diameter of $0.2-0.4 \mu \mathrm{m}$ wide and $0.4-1.0 \mu \mathrm{m}$ length. In life cycle, the bacteria occur in two forms: the "large cell variant" (LCV) which are a vegetative intracellular form and "small cell variant" (SCV), which are spore-like forms. They are distinguished by morphology of the cell and peptidoglycan content in the cell wall. LCV reach $1 \mu \mathrm{m}$ and are characterized by irregular shape, loose nucleoid structure and granular or filamentous cytoplasm. The size of the SCV varies between 0.2 and $0.4 \mu \mathrm{m}$, and is characterized as a rod shape with thick wall and highly condensed chromatin.

It has been observed by Coleman that transition from LCV to SCV occurs in host cells phagosomes in acidic environment conditions of $\mathrm{pH}=4.8$. This process has been monitored in cells in vitro. During the first two days of intracellular growth, transformation of SCV to LCV takes place. The number of LCV cells dominates during the four days of rapid growth phase (time between cell division of about 10 hours). Stationary phase begins approximately at 6 day after infection. In this phase the process of the reappearance of SCV also begins. Their number increase at 8 day after infection.

It was estimated that among 675 of $C$. burnetii proteins, a few dozen of them are involved in the process of sporulation. Measuring the intensiveness of proteins synthesis in SCV and LCV, it was established that the synthesis of 48 proteins increased twice or more during the formation of LCV. Fifteen of them have been identified by mass spectrometry. They are responsible mostly for bacterial physiological activity. These activities include: transcription ( $\mathrm{N}$ utilization protein - NusA), translation (ribosomal proteins RpsA and RplI and elongation factor EF-Tu), cell division (cell division protein FtsZ), chromosome partitioning (segregation and condensation protein $\mathrm{ScpB}$ and chromosome partitioning protein $\mathrm{ParB}$ ), riboflavin biosynthesis (synthase $\mathrm{RibH})$, and protein folding $(60-\mathrm{kDa}$ chaperone GroEL and chaperone protein HtpG). Synthesis of 6 other proteins increased in the SCV phase including proteins involved in outer membrane stability TolB, GTP binding protein (Era), cystathionine beta-lyase (MetC). They are mainly involved in processes of cell resistance to environmental conditions (Coleman et al., 2004; Coleman et al., 2007).

The process of sporulation and the formation of $\mathrm{SCV}$, was observed in vivo with electron microscopy (Avakyan etal., 1983; McCaul et al., 1981; McCaul et al., 1994). C. burnetii presented pleomorphism with occuring of both cell types. A spore-like formation was observed in large vegetative cells. The process began at the polar regions of the LCV and appearing SCV were identified by high density of core, membrane-like structures, peptidoglycan and trilaminar outer membrane (McCaul et al., 1994).

Decreased metabolic activity, condensed chromatin and thick wall of SCV determine resistance to physical and chemical factors. These features makes them capable to live in the external environment. In this form the bacteria are able to survive for 30 days at the $4^{\circ} \mathrm{C}$, and at $60^{\circ} \mathrm{C}$ for one hour. Their survival in milk at $63^{\circ} \mathrm{C}$ for 30 minutes or $74^{\circ} \mathrm{C}$ for 15 seconds has been also observed. They are resistant to biocides such as lysol $5 \%$, formalin $5 \%$, sodium hypochloride $0.5 \%$, sodium hydroxide $5 \%$ or ammonium chloride $10 \%$ (Babudieri, 1959; Scott and Williams, 1990). Capacity of spore formation, determined the resistance to adverse environmental conditions. In nature, C. burnetii bacteria can survive two years in animal feces, six months in dried blood and a month in dried urine (Kishimoto et al., 1979). 


\section{Cell wall of C. burnetii}

As Gram-negative bacteria, C. burnetii show a typical cell wall structure, characteristic for that group of microorganisms consisting of the cell wall with outer membrane. The wall contains the peptidoglycan layer which is composed of $\mathrm{N}$-acetylmuramic acid, $\mathrm{N}$-acetylglucosamine, D-alanine, D-glutamic acid, and mesodiaminopimelic acid. The outer membrane includes a complex of lipopolysaccharide (LPS) (Amano and Williams, 1984).

Regardless of the morphological LCV and SCV forms, C. burnetii demonstrate antigenic variation of LPS chemical composition, similar to that observed in the Enterobacteriaceae family. These variations determine the form of the bacterial cells in phase I or phase II. Phase I is the natural form, occurring in infected animals and humans and is characterized by high infectivity. Phase II is not very infectious and occurs in laboratory conditions after passages in cell lines or chicken embryos.

The O-antigenic polysaccharide of phase I LPS is composed of galactosaminuronyl-alpha- $(1,6)$-glucosamine disaccharide and two other unique sugars: 6-deoxy-3-C-methyl-gulose (virenose) and dihydroxystreptose 3-C-(hydroxymethyl)-lyxose (Amano et al., 1984; Schramek et al., 1985; Slabá et al., 2003). They are located at the $\mathrm{O}$-polysaccharide terminus and are responsible for antigenic specificity. Attachment sites of phase I-specific sugars to the LPS II-core are: the 3-position of a branched heptose and, presumably, the 4-position of a terminal D-mannose (Mayer et al., 1988). Additionally, it contains D-mannose, D-glucose D-glyceromannoheptose, glucosamine, ethanolamine acid, 3-deoxy-D-mannooctulose and 9 other unidentified compounds also (Amano et al., 1984).

Phase II LPS is a reduced form and does not contain branched sugar chains. Reducing processes of the LPS chain are regulated at the genome level. Deletions in the chromosomal DNA occur in the region containing genes essential for process of LPS biosynthesis, including genes of epimerase, dehydratase, glycosyl transferases, or primary production virenose C-methyltransferase gene. The composition of this region also includes genes responsible for synthesis pyruvate dehydrogenases and adenosyl sulfotransferases. These molecular changes appear during passages in cell lines or in chicken embryos (Hoover et al., 2002; Denison et al., 2007).

Phase I LPS of C. burnetii cells is responsible for their virulence. It affects the phagocytosis process of monocytes and macrophages. It stimulates $\alpha_{v} \beta_{3}$ integrin to transform it into an active form, allowing adhesion of the pathogen to the surface of monocyte as the first step of phagocytosis. It also causes conversion of
F-actin into the fibrillar form in macrophages, which leads to the formation of cytoplasmic pseudopodia surrounding bacterial cells (Honstettre et al., 2004). Both processes are stimulated by creation a complex with Toll-like receptor 4 (TLR4). Such complexes also stimulate the production of IFN- $\gamma$ and TNF cytokines which are essential in the early immune response to the infection.

After successfully evading host defense mechanisms, C. burnetii bacteria are able to inhibit apoptosis to survive and to multiply inside the cells. C. burnetii infection affects the expression of multiple apoptosisrelated genes and resulting in increased synthesis of the antiapoptotic proteins such as A1/Bfl-1 (member of Bcl-2 family antiapoptotic proteins), c-IAP2 (inhibitors of apoptosis protein family member - IAP), prosurvival kinases Akt and Erk1/2 (extracellular signal-regulated kinases 1 and 2). C. burnetii infection of THP-1 human macrophage-like cells caused increased levels of phosphorylated c-Jun, Hsp27, Jun N-terminal protein kinase, and p38 protein. This pathogen can interfere with the intrinsic cell death pathway during infection by producing proteins that either directly or indirectly prevent release of cytochrome $c$ from mitochondria. (Voth et al., 2007; Voth and Heinzen, 2009; Lührmann and Roy, 2007). C. burnetii bacteria may inhibit the process of apoptosis in the host cells for at least 4 weeks (Chmielewski and Tylewska-Wierzbanowska, 2011). This phenomen can permit bacteria to survive intracellularly in the host and to develop chronic disease.

\section{Genome of C. burnetii}

C. burnetii possesses a small chromosome of $5 \mathrm{Mbp}$ in size, and one to five plasmids of $30-51 \mathrm{kbp}$, which contained about $2 \%$ of the genetic information. So far, 2134 gene sequences have been identified. These genes are involved in adhesion, invasion, intracellular trafficking, host modulation and other virulence-related functions. Among all detected gene sequences, 719 $(33.7 \%)$ have no homologues of gene sequences known in other bacteria and enclosed in genetic databases. These hypothetical genes may be responsible for functions important in the unique developmental cycle of C. burnetii. Genome analysis has also revealed the presence of numerous mobile elements and pseudogenes which are the dysfunctional relatives of genes that have lost their protein-coding ability. It indicates the ongoing process of genome reduction (Seshadri et al., 2003).

However, there is only one species within Coxiella genus, the diversity of clinical symptoms indicates differences in the pathogenicity of isolated strains. Recently their heterogeneity and association of particular strains with acute disease were investigated with molecular genotyping techniques. 
In nineties of the XX century determination of plasmid profiles allowed to distinguish five types of C. burnetii (types named as plasmids): QpH1, QpRS, QpDV, QpDG and plasmidless type. Initially, it made possible to identify pathogenicity, since particular types were observed among strains isolated from patients with acute or chronic Q fever.

Subsequently restriction fragment length polymorphism (RFLP) analysis of chromosomal and plasmid DNA distinguished six genomic groups (I to VI). These groups correlate well with plasmid profiles and they are points of reference for new molecular methods for characterizing C. burnetii strains (Hendrix et al., 1991, Nguyen and Hirai, 1999) (Table I).

Plasmids QpH1, in size of $36 \mathrm{kbp}$ occur in strains of genomic groups I to III in one to three copies in the cell and are mainly associated with acute infection. Group I includes strains: Nine Mile RSA 493, Australia QD RSA435, California 33 RSA329, Ohio 314 RSA270, Dyer RSA345, group II includes Henzerling RSA331 and M44 RSA459, and group III includes Idaho Goat Q195, Koka. Plasmid QpRS was detected in strains of group IV isolated from miscarrying goats and from humans with endocarditis (MSU Goat Q177, Priscilla Q177, Canada Goat Q218, K Q154, P Q173, F Q228). Plasmid QpDV in size of $30 \mathrm{kbp}$, is also isolated from patients with acute and chronic Q fever (Valkova and Kazár, 1995). Plasmidless strains (Scurry Q217, Q229, G212, L Q216) belong to the V group and contain homologous to the QpRS sequences, located in chromosomal DNA. Plasmid QpDG (42 kbp) is characteristic for the genomic group VI isolates, from rodents and cattle (Dugway 7E22-57, Z257, Z3027) and from patients with both acute and chronic $Q$ fever (Hendrix et al., 1991; Mallavia, 1991; Willems et al., 1993). It was shown that this plasmid is almost identical with the plasmid QpH1 (Jäger et al., 2002). Analysis of genomic DNA with pulsed field gel electrophoresis (PFGE) showed greater variation and allowed the dis- tinction of 20 groups of C. burnetii strains (Jäger et al., 1998). The first four groups correspond to previously described genomic groups: I, IV, V and VI. This method showed phylogenetic relatedness of bacteria occurring in the same parts of the world, but there was no correlation between the different groups separated in the PFGE analysis and virulence. Pathogens isolated from patients with acute or chronic Q fever have the same restriction profile.

Sequencing of the whole genome of $C$. burnetii (strain Nine Mile) in 2003, allowed the introduction of genotyping this organism by MST (multispacer sequence typing). Selected region of $16 / 23 \mathrm{~S}$ ribosomal DNA, is used in the genotyping of many other bacteria. Based on the sequencing of 10 different parts of the region, among the 173 previously characterized strains, 34 genotypes sequence types (ST) from ST1 to ST34 were distinguished and divided into three phylogenetically homogeneous groups. This classification corresponds to the groups established by plasmid DNA analysis.

The first group (containing the strains with the plasmids QpRS and/or QpDV) includes types of ST1-ST10 and ST26, ST28, ST30, ST31. The second group (with plasmid QpH1) are the types: ST11-ST20, ST22, ST25, ST27, ST29, ST32, ST33. The third group include ST21 only (QpH1 or plasmidless strains). In all groups, there are strains isolated in Europe, North America, Asia and Africa. MST show that the same sequence types can occur in distant parts of the world. For example, ST16 strains were isolated on four continents. It may be the proof of its spread with infected humans, animals and their products or ticks. This method has shown the correlation between ST1, ST4, ST16, ST18 and acute Q fever, and correlation between ST8 and chronic form of disease (Glazunowa et al. 2005).

\section{C. burnetii reservoir and mode of transmission}

$\mathrm{Q}$ fever is a widespread in the world zoonosis. Its main reservoir in the rural environment are farm

Table I

C. burnetii genomic groups

\begin{tabular}{|l|c|c|l|c|}
\hline $\begin{array}{l}\text { Plasmid Profiling } \\
\text { 5 plasmid profiles }\end{array}$ & $\begin{array}{c}\text { RFLP analysis }^{2} \\
\text { 6 genomic groups }\end{array}$ & $\begin{array}{c}\text { PFGE }^{3} \\
\text { 20 restriction patterns }\end{array}$ & $\begin{array}{c}\text { MST }^{4} \\
\text { 34 sequence types (ST) }\end{array}$ & $\begin{array}{c}\text { MLVA }^{5} \\
22 \text { panels }^{\text {I }}\end{array}$ \\
\hline QpH1 & I & I & ST11-ST20, ST22, ST25, ST27, ST29, ST32, ST33 & $1-2,4-14$ \\
& II & ND & & \\
\hline Plasmidless & VD & V & ST21 & 3 \\
\hline QpDV & VII & ND & ST1-ST10 and ST26, ST28, ST30, ST31 & 17 \\
\hline QpRS & IV & IV & & $15-16,18-22$ \\
\hline QpDG & VI & VI & - & - \\
\hline Not established & - & $1-16$ & - & - \\
\hline
\end{tabular}

${ }^{1}$ according to Willems, et al. 1993; ${ }^{2}$ according to Hendrix, et al. 1991 and Beare et al. 2006; ${ }^{3}$ according to Jäger, et al. 1998

${ }^{4}$ according to Glazunova, et al. 2005; ${ }^{5}$ according to Arriccau-Bouvery, et al. 2006 (genotyping in 1-22 panels); ${ }^{6}$ not determined 
animals: cows, sheep, goats, and urban pets such as dogs, cats, rabbits. In acute infection these bacteria are detected in various internal organs such as lungs, liver, spleen, and in excretion in urine, faeces and milk. During childbirth, they occur in large number in the amniotic fluid and placenta. It was estimated that one gram of placenta of infected animals may contain $10^{9}$ C. burnetii bacteria, and one millilitre of milk $10^{3}$ bacterial cells (Babudieri, 1959). It has been shown that 1-10 bacterial cells (Ormsbee et al., 1978) can cause $\mathrm{Q}$ fever in human.

The environmental reservoir of C.burnetii are wild animals: mammals, birds, reptiles and also ticks. Antibodies and/or DNA of the pathogen was found in deer, mouflon, coyotes, foxes, raccoons, mice and rabbits (Barandika et al., 2007, McQuiston and Childs, 2002, Ruiz-Fons et al. 2008, Dorko et al., 2009, Stein and Raoult, 1999). Migratory birds may carry microorganisms over long distances, even in areas previously known as free of Q fever (Ionnou et al., 2009). C. burnetii was also isolated from the liver and spleen of turtles, snakes and lizards. Potential source of infection for the snakes are infected small rodents (Yadav and Sethi, 1979). Ticks are vital reservoir in natural environment. C. burnetii bacteria were detected in more than 40 tick's species, mainly in those belonging to the genus Ixodes, Rhipicephalus, Amblyomma, and Dermacentor. Moreover, ticks may play a role of a vector of $\mathrm{Q}$ fever. C. burnetii bacteria have the ability to penetrate their digestive tract and multiply in epithelial cells of the intestine and in the midgut. Bacteria can be transmitted from feeding tick with excreted feces which contaminate fur of animals. Next C. burnetii is transmitted to healthy individuals with a dust or aerosol. Tick's participation in the epidemiological process in many cases is limited to the passive spread of the pathogen in the environment and is not a necessary link in the epidemical chain (Maurin and Raoult, 1999; Rehacek and Tarasevich, 1988). All these data indicate that C. burnetii has no specific reservoir in the environment, and that they can provide all vertebrates.

Recently, it has been found that free-living protozoa amoeba Acanthamoeba castellani may also be a reservoir of the pathogen. This is a cosmopolitan protozoan occurring in fresh water, damp soil and air. The intra-amoebal location of C. burnetii cells was observed by microscopy. After 3 days of cultivation, bacteria were found in vacuoles within the amoebae in a large cell variant form. Bacteria were not found free in cytoplasm. Viable bacteria were seen for 18 days and after that time some of them appeared as sporelike forms demonstrating the ability of C. burnetii to undergo differentiation process within amoebae. These results indicate that free-living amoebae could be an intracellular niche for the spore formation and sur- vival of C. burnetii in the environment (La Scola and Raoult, 2001) The bacteria spread in the environment after delivery by infected animals and they could be ingested by soil amoebae. Then they can differentiate into a spore-like forms inside, and the infected amoebae can be transmitted with the wind. Q fever was observed in areas distant for several kilometres from the farms with infected animals. These cases were the result of the C. burnetii carried with the dust by the mistral blowing from infected areas (Tissot-Dupont et al., 1999; TissotDupont et al., 2004).

Human infection could occur through the inhalation of infected amoebae as it has been described in the epidemiology of Legionella pneumophila - closely related phylogenetically to C.burnetii (Greub and Raoult, 2004). In addition these two pathogens have some other common features. Legionella can be cultured in living protozoa (Rowbotham, 1983) and C. burnetii is cultured in different eukaryotic cell lines (Gouriet et al., 2005). During infection of humans both of these pathogens multiply in alveolar macrophages inside a phagosome. L. pneumophila and C. burnetii are the only two bacteria known today to utilize a typeIVB secretion system for pathogenesis. This system play an important role in creating the specialized vacuole that supports C.burnetii replication within the host cell (Segal et al., 2005). All known intracellular species (including both pathogens) have common evolutionary origin confirmed by detection of over 200 ortholog genes. Moreover, C. burnetii and L. pneumophila obviously may exchange genes in the amoebas with other bacteria (Gimenez et al., 2011).

Implication of ability to intracellular existence in free living amoebas, may be transmission of the $\mathrm{Q}$ fever agent by air conditioning as it has been observed in Legionella infections. This etiology should be analyzed if atypical pneumonia appears among patients exposed to such system. For the first time the role of air conditioning as a potential source of a $\mathrm{Q}$ fever was established in 2005 in Israel. Infection was detected among 322 students and employees eating in dining room of local urban school (Amitai et al., 2010).

The route of infection can determine clinical symptoms of Q fever (Marrie et al., 1996). The main route of C. burnetii transmission from animals to humans is the inhalation of contaminated aerosols. Less important is oral route of infection. Consumption of raw milk and its products but also tobacco smoking, have been reported as a risk factor of disease (Fishbein and Raoult, 1992; Hatchette et al., 2001).

Transmission among humans through sexual contacts has been described (Kruszewska et al., 1996; Tylewska-Wierzbanowska et al., 1996). This route of infection was also confirmed experimentally in mice. From intraperitoneal infected male mice, spermatozoa 
were isolated and examined with electron microscopy. C. burnetii formed agglomerations of spermatozoa with bacteria attached to their heads and leukocytes. Infection was transmitted by sexual contact from infected male mice to uninfected female mice. This was confirmed by humoral response to the antigens of both phases (Kruszewska and Tylewska-Wierzbanowska, 1991; 1993). These findings suggested hypothesis of the sexual transmission of $\mathrm{Q}$ fever in artificially inseminated cattle. Such hypothesis was confirmed by examination of serum and semen samples from bulls suspected to be infected with C. burnetii. Among seropositive bulls, viable bacteria have been detected in semen with indirect immunofluorescence assay and strains of C. burnetii have been isolated (Kruszewska and TylewskaWierzbanowska, 1997).

Other than sexual transmission from man to man may occur sporadically. Such infections have been described during autopsy from necropsy material, by blood transfusion and after contact with infected parturient woman (Maurin and Raoult, 1999; Rehacek and Tarasevich, 1988)

\section{Clinical course of disease}

$Q$ fever shows a wide range of acute and chronic manifestations. The incubation time is $1-3$ weeks. About $60 \%$ of infected persons are asymptomatic. The others have a non-specific influenza-like illness with fever, headache, sweats, non productive cough, myalgias and arthralgias in acute phase of infection. Most of them develop atypical pneumonia confirmed with the chest radiograph and/or hepatitis. In patients with hepatitis, the liver biopsy reveals diffuse granulomatous changes, and blood testing shows high levels of alkaline phosphatase and transaminases. About 5\% of infected patients required hospitalization due to respiratory distress or hepatitis (Tissot Dupont et al., 1992; Maurin and Raoult 1999). Infection of the central and peripheral nervous system is reported as a rare feature and manifests as a meningitis, meningoencephalitis, Guillain-Barre syndrome. The majority of patients present with severe headache, confusion, psychiatric disturbances, peripheral neuropathies and neurological deficits. Cranial nerve palsy and blurred vision is observed less frequently. Small pleocytosis and elevated protein levels are detected in cerebrospinal fluid in approximately $30 \%$ of these patients (Bernit et al., 2002; Kofteridis et al., 2004, Ong et al. 2010). Rare manifestations of acute Q fever affect cardiovascular system (myocarditis and pericarditis) and skin. Myocarditis is usually asymptomatic and is detected only in the electrocardiogram (T wave inversion, ST elevation). It can be accompanied by arrhythmia, tachycardia and hypoxemia leading to severe cardio-vascular disorders in some cases (Chevalier et al., 1997; Vogiatzis et al.,
2008; Fournier et al., 2001). Pericarditis is manifested as a pain in the chest. It is often not recognized due to similar symptoms accompanying atypical pneumonia (Levy et al., 1999, Bautista-Hernandez et al., 2004). In $5-21 \%$ of patients can also be observed macular or papular rash on the skin (Maurin and Raoult, 1999).

Chronic $\mathrm{Q}$ fever occurs in less than $1 \%$ of cases. It is developed months or years after infection, and affects mainly patients with the mitral or aortic valve defects, with vascular diseases or immune defect. Myocarditis $(60-70 \%)$ and vascular infections (about $9 \%$ ) are the most common manifestation in the chronic form of disease (Botelho-Nevers et al., 2007, Maurin and Raoult, 1999; Varma et al., 1980). Clinical forms range from asymptomatic to congestive heart failure with mortality of about 30-40\% (Fennolar et al., 2006; Karakousis et al., 2006). Death rate has decreased to $5 \%$ over the past 10 years due to better diagnosis and the introduction of treatment with several antibiotics simultaneously (Raoult et al., 1999).

The second most common form of chronic Q fever are vascular infections of large blood vessels. Serious sequels occur in patients with aortic aneurysm or vascular grafts. Infection with C.burnetii may lead to massive hemorrhage from the wall of the aneurysm or from the anastomosis. Mortality among these patients reaches 25\% (Botelho-Nevers et al., 2007; Ellis et al., 1983; Sessa et al., 2005).

Rare manifestations involve liver, osteoarticular and respiratory systems. Chronic hepatitis has been reported mainly as a concomitant symptom with chronic myocarditis (Westlake et al., 1987). In some individuals it may be the only manifestation of chronic $\mathrm{Q}$ fever and can be confirmed by detection of high levels of antibodies to phase I antigen (Yebra et al., 1988).

Osteoarthritis is diagnosed mainly in children. Inflammation of the hip joint, lumbar sopondylitis, discitis and osteomyelitis have been reported (Cottalorda etal., 1995; Ortolá et al., 1992; Raoult et al., 1989). Bronchial tumors may occur in respiratory system as a result of long-lasting pneumonia. Cumulation of monocytes in the alveolar closes bronchioles lumen. This mechanism has been observed in the histopathological examination of pulmonary tissue (Janigan and Marrie, 1983).

There are a few data on the consequences of $\mathrm{Q}$ fever during pregnancy. In untreated women is associated with high fetal mortality. Normal outcome and a healthy child at delivery had only $18.9 \%$ of monitored untreated women. So far congenital teratogenic defects in children of untreated mothers have not been observed. Infection with C. burnetii can cause premature delivery ( $44.7 \%$ of cases), abortion ( $26 \%$ of cases), intrauterine fetal death intrauterine growth retardation. C. burnetii penetration of the placenta and fetus infection in utero 
are well documented. The bacteria colonize and multiply in the uterus, placenta and mammary glands. It leads to placenta insufficiency following vasculitis and thrombosis (Stein and Raoult, 1998).

Infection during pregnancy is associated with higher risk of developing chronic form of the disease and spontaneous abortions in the future. Q fever can also be activated during the next pregnancy, and therefore patients require regular monitoring and long-term cotrimoxazole therapy (Carpocino et al., 2009; Raoult et al., 2002). It has been proved that a late sequel of acute Q fever may be chronic fatigue syndrome also (Ayres et al., 1996).

$\mathrm{Q}$ fever is uncommon in children. The main clinical symptoms are pneumonia with pleural effusion, meningitis, rarely hepatitis (with elevated transaminases) and hemolytic-uremic syndrome. Fever is ascertained in all infected ones and it lasts for 10 days. About half of affected children complain of headache, abdominal pain, nausea, and fatigue (Maltezou et al., 2004).

\section{Treatment of $\mathbf{Q}$ fever}

Treatment of acute $Q$ fever should be started within the first 3 days of diseases. The drugs of choice are tetracycline $(4 \times 500 \mathrm{mg})$, primarily doxycycline $(2 \times 100 \mathrm{mg})$, administered for 14 days. An alternative for tetracyclines are fluoroquinolones $(3 \times 200 \mathrm{mg})$ for 14-21 days, or pefloxacin (400 mg) administered 14-2 days (Raoult, 1993; Maurin and Raoult, 1999). Fluoroquinolones alkalinizes the phagolysosomes of infected host cells and could be used in patients with Q fever meningoencephalitis considering their good penetration to cerebrospinal fluid. Effective treatment were also observed after macrolides applications. Clinical studies have shown that erythromycin administered in doses of $500 \mathrm{mg}$ every 6 hours for 10 days, is effective. Comparing duration of treatment with erythromycin, clarithromycin, roxithromycine or $\beta$-lactam antibiotics with doxycycline, normalization of body temperature was longer on the average of one day in groups of patients treated with clarithromycin $(2 \times 500 \mathrm{mg})$, erythromycin $(3 \times 500 \mathrm{mg})$ and roxithromycin, and by nearly 3 days longer in patients receiving $\beta$-lactams (Gikas et al., 2001)

Chronic Q fever (myocarditis) requires a long treatment with tetracycline (months and years) and is one of the longest duration of antibiotic therapy in bacterial diseases. Often the treatment leads to failure or relapse (Ellis et al., 1983). Combined treatment, including tetracycline with lincomycin, co-trimoxazole with tetracycline or rifampicin with tetracycline (Tobin etal., 1982, Varma et al., 1980) does not give the expected results. Despite the use of them for several years C. burnetii was isolated from valves. Good therapeutic results were obtained using a combination of doxycycline with ofloxacin. Mortality decreased to about 5\%, however, proportion of relapses was still high (64\%). This proportion dropped to $14 \%$ after the 18 months treatment with doxycycline $(2 \times 100 \mathrm{mg})$ and chloroquine $(3 \times 200 \mathrm{mg})$. This scheme is currently recommended in the treatment of chronic $Q$ fever. In clinical cases, in which of chloroquine is contraindicated, doxycycline $(2 \times 100 \mathrm{mg})$ with ofloxacin $(3 \times 200 \mathrm{mg})$ for at least 3 years is administered (Fennolar et al., 2006; Maurin and Raoult, 1999)

\section{Sensitivity of $C$. burnetii to antibiotics}

Antibiotic sensitivity has been studied in animal models, chicken embryos and cell lines (Baca and Yeaman, 1991; Raoult, 1991; Spicer et al., 1981). Animal models were used for testing sensitivity to antibiotics in acute infection only.

In these studies resistance to streptomycin treatment to infected guinea pigs has been proved. In in vitro studies, the antibiotics influence on the growth of C. burnetii in chicken embryos was examined. Extension of survival time was revealed in infected embryos after administration of antibiotics. It was found that rifampicin, doxycycline, oxytetracycline and trimethoprim are effective but their use has shown a bacteriostatic effect against C. burnetii infection only. Tested strains demonstrated also the resistance to penicillin, aminoglycoside, erythromycin, clindamycin and cephalotin (Spicer et al., 1981).

With the development of cell lines culture techniques it was possible to use them to determine sensitivity of the bacteria to antibiotics. The study was conducted in line L-929 (mouse fibroblasts) freshly (few days) and chronically (over 100 days) infected with different strains of C. burnetii. Antibiotics labeled with isotopes were added to infected cultures and their accumulation in bacterial cells was measured (Baca and Yeaman, 1991). It was shown, that in vitro C. burnetii strains isolated from chronic Q fever patients, exhibit significant differences in reaction to tetracycline, rifampicin and fluoroquinolones. Priscilla strain, has been shown a significant resistance to these antibiotics, comparing to the " $\mathrm{S}$ " isolate which was much more sensitive in chronically infected cells (300 days). The "S" strain was significantly more resistant to doxycycline and ciprofloxacin compared to the acute $\mathrm{Q}$ fever-implicated Nine Mile strain. Their sensitivity to antibiotics was found to be moderate in fresh infected ( 22 days) cell culture. It suggests that C. burnetii isolates, which may be responsible for the clearly different $Q$ fever symptoms exhibit a spectrum of antibiotic sensitivity ranging from very sensitive acute-implicate Nine Mile strain, to moderately susceptible chronic-implicated "S" isolate, and to moderately resistant chronic-implicated Priscilla isolate (Yeaman and Baca, 1990). 
It has been demonstrated that bacteriostatic activity of doxycycline, could be changed into bactericidal, by the adding of amantadine or chloroquine to the fresh infected cell line. They raised the $\mathrm{pH}$ of infected cells and improve the efficiency of doxycycline (Maurin and Raoult, 1999; Raoult et al., 1999).

The machanisms of antibiotic resistance are poorly characterized. Genome-based studies have shown that the main mechanism of $C$. burnetii resistance to fluoroquinolones is based on mutations in genomic quinolone-resistance-determining region (QRDR). About 15 bacterial proteins are involved in these cellular processes (Vranakis et al., 2011). The best known mechanism is that caused by nucleotide mutation in DNA gyrase encoding genes (gyrA and gyrB) and topoisomerase IV genes (in subunits: parC and parE), leading to an amino acid substitution (Vranakis et al., 2010).

\section{Q fever in Europe}

In Europe for the first time Q fever was detected in Greece during the World War II. C. burnetii strain was isolated in guinea pig injected with the blood of a patient infected during an outbreak in Athens in 1943. The disease resembling influenza, has been named by Germans a "Balkan Grippe". In the years 1944 and 1945 epidemics of Q fever occurred among U.S. troops stationed in Italy and at Corsica. After World War II, an endemic +area of Q fever in Europe represented Portugal, Spain, southern France, Italy, Switzerland, southern Germany, Slovakia, Great Britain, the Balkans and the southern part of the USSR. In central Europe the source of infection for humans mainly were cattle and sheep, and in southern Europe goats (Rehacek et al., 1988). Until the eighties of the $20^{\text {th }}$ century Q fever was reported as a local outbreaks or sporadic cases (Marrie et al., 1988; Marrie etal., 1986; Meiklejohn et al., 1981; Salmon et al., 1982; Spelman, 1982; Tissot Dupont et al., 1992).

At the turn of the centuries, besides local foci, major outbreaks with large number of infection cases have occurred (Lyytikäinen et al., 1998; Panaiotov et al., 2009; Dupuis etal., 1987; King etal., 2011; Carrieri etal., 2002). This phenomen is related to change sin animal farm organization and their structure. Because of the great demand for goat milk products, the number of herds of these animals has increased. Intensive breeding and transport of goats between farms favor the spread of infection among these animals. The cause of the pathogen spread among humans is the use of goat feces as a natural fertilizer close to the towns and transport the animals through the densely populated urban areas (Enserink et al., 2010).

For the first time, that process was observed in Bulgaria in nineties of the twentieth century. Greater demand for goat milk products, caused that the num- ber of goats tripled and replaced cattle and sheep as the main source of human C. burnetii infections. Hundreds of serologically confirmed human cases of acute Q fever have occurred and chronic disease as endocarditis were also observed (Serbezov etal. 1999). Since 2007 in the Netherlands the largest Q-fever epidemic ever reported has been lasting up today. During 2007-10 over 4,000 human cases have been recorded, with 14 deaths. The main reason of the epidemic is the increase in the intensity of goat breeding. The number of those animals has quadrupled since 1995 to more than 350 thousand. Geographically, farms are located often close together. Transport of goats between them through densely populated areas facilitating spread of C. burnetii in environment. Genetic typing with VNTR (variable-number tandem repeat analysis) has shown that animals and humans are infected by a single subtype suggesting its better propagation than others. Additionally, animal vaccination is not effective. These are the probable reasons of the spread of the epidemic (Speelman, 2010; Tillburg et al., 2012).

The proximity of large numbers of people not related to livestock production in contact with infected animals is another cause of large outbreaks. Such two foci occurred in Germany in 2003 and 2005. In the first one, 299 patients were registered. The source were infected sheep sold in the local market visited by large number of customers. In the second one (331 patients), infected sheep were grazed a few dozen meters away from housing developments (Gilsdorf et al., 2008; Porten et al., 2006).

\section{$Q$ fever in Poland}

Two sources of the outbreaks have been observed in Poland: the import of infected animals or their products and natural domestic foci (Anusz, 1995, Anusz et al., 1996, Chrzanowski et al. 1960). In 1956 the first outbreak of $\mathrm{Q}$ fever was recorded in Owczary near Gorlice (south-eastern Poland). In April and May 63 persons were affected and among tested 35 cases were confirmed with serology. Epidemiological investigations revealed that the source of infection was a sheep flock imported from Romania (Lutyński, 1956). Tested wool samples from these animals were the source of the secondary outbreaks in laboratory of Zootechnical Institute in Kraków (20 cases) and National Institute of Hygiene in Warsaw (17 cases). In 1962 Q fever in the furrier factory was reported. Twenty six persons were infected, and the source of infection were skins from American sheep (Gawron and Wagner, 1962). In 1985 Q fever outbreak occurred in Olsztyn region in the factory of leather industry. Five persons were hospitalized in this outbreak. (Stempień et al., 1985). In 1992 $\mathrm{Q}$ fever was recognized among 18 workers of a tannery in Malopolska voivodship (southern Poland). Antibod- 
ies to C. burnetii were detected in all 18 individuals who had been in contact with fells imported from Mongolia (Tylewska-Wierzbanowska et al., 1996). These fells were contaminated with infected ticks

From 1956 until 2005 several domestic outbreaks of Q fever were described (Anusz et al., 1986; Mikołajczyk et al., 1986; Tylewska-Wierzbanowska et al., 1993; 1996).

In 1983 an epidemic of Q fever among humans and animals was recognized near Zamość (Lubelskie voivodship in eastern Poland). More than one thousand people showed high levels of antibodies and C. burnetii strains were isolated from human as well as cow placentas. Epidemiological investigations did not detect the source of infection and there was no any import of animals or their products to this region (Mikołajczyk et al., 1986). In 1985 the focus of Q fever was found in the Bialowieza primeval forest (eastern Poland) among bisons, cattle and sheep. (Anusz et al., 1991b). A serological survey in small mammals revealed the presence of specific antibodies in mice, rats, shrews, field-voles in the Olsztyn region in north-eastern Poland (Anusz et al., 1991a). C. burnetii caused outbreaks in 1985 and 1986 in two farms in olsztyńskie voivodship. In one of them, among 686 person examined for the presence of C. burnetii antibodies, $11 \%$ were seropositive. Specific antibodies were also found in 19\% of tested cattle. Rodents were not infected. These results suggested the existence of a natural C. burnetii reservoir (Anusz et al. 1986). Circulation of the pathogen in the environment was first confirmed in 1989 by isolation of C. burnetii from the tick Ixodes ricinus found in this focus (Anusz et al., 1996).

From 1973 to 1991 a serological survey of Q fever among cattle and sheep has been performed in Wielkopolska voivodship (western Poland). From 1973 to 1985 over 28 thousands blood samples derived from cattle and sheep have been tested. All were seronegative. In 1986 the first seropositive cattle were found (5.5\%) and in the next year the percentage increased to $16.3 \%$. In 1988 serum antibodies to C. burnetii were detected in $25.9 \%$ cattle. At the same time sheep living in the neighborhood were free of infection. In the consecutive years, the percentage of seropositive animals decreased and in 1991 was only 3.2\%. In this time, a serological survey was performed among individuals who had professional contact with the animals. In southern Wielkopolska, among 4214 persons tested, 34.4\% were seropositive. From 1988 to 1991, in the central part of this region, antibodies to $C$. burnetii have been detected in $22.7 \%$ of 6396 people tested. In the next years, the percentage fluctuated from 16.6 to $34.7 \%$ (TylewskaWierzbanowska et al. 1991; 1993)

In 1992 an outbreak of Q fever was detected at a farm in Dolnoslaskie voivodship (southern Poland). The disease was recognized serologically in 25 per- sons (27 tested). It was found that C. burnetii infection spread among cattle and these animals were the source of infection for humans (Tylewska-Wierzbanowska et al., 1996).

The source in those epidemics was unclear. There was no any import of animals at that time. The only probable source of infection could be imported bull semen contaminated with C. burnetii bacteria. Outbreak invastigation confirmed transmission of $Q$ fever by artificially insemination of cattle (Kruszewska et al., 1997).

In 1993 several cases of Q fever were observed among people living in various regions of the country. Epidemiological investigations revealed that the infected patients were seasonal workers employed during the shearing time in Spain. Specific serum antibodies reached the titer 512 and C. burnetii strains were isolated from the urine and semen of 2 patients. At the same time symptoms of the disease and increased levels of specific serum antibodies were detected in their wives who remained in Poland and had no any contact with the animals. Transmission among humans through sexual contact was confirmed. Since the other family members have not shown infectious symptoms, sexual transmission was postulated (Kruszewska et al., 1996; Tylewska-Wierzbanowska et al., 1996).

MST analysis of C. burnetii strains isolated in Poland between the sixties and the eighties of the $20^{\text {th }}$ century, showed that all of them represent ST18 (sequence type), although MLVA typing showed their genotypic heterogeneity. Strain isolated in 1956 from sheep belongs to unique MST pattern ST16 which have never been recognized later in Poland (Chmielewski et. al., 2009). It suggests that this imported strain was effectively eliminated due to sanitary procedures applied. This particular strain did not spread later on Polish territory, even though it is known that C. burnetii strains with ST16 profile occur in Europe (Romania, Germany and France) as well as on other continents. It has been established, that ST18 and ST16 types appear in strains isolated from patients with acute form of the disease and they have never been present in strains isolated from chronic Q fever cases. There is a wide variety of isolated strains in countries neighboring with Poland. In Germany there are at least six sequence types, and in Slovak Republic at least three (ArricauBouvery et al., 2006).

From 2005 to 2010, five Q fever outbreaks have been recognized in southern Poland. Over sixty human cases have been reported. These outbreaks demonstrate that the source of infection for humans are infected cattle (in press). In 2007 epidemiological study was carried out in Poland to determine prevalence of C. burnetii antibodies in the 48 herds of goats located in different parts of the country. The survey did not revealed antibodies to C. burnetii in tested animals (Czopowicz et al., 2010). 
So far, there have been no reported goat-to-human transmissions of $C$. burnetii in Poland.

All human cases diagnosed to this time, represented acute form of infection. Chronic Q fever cases (endocarditis) in previous and recent $\mathrm{Q}$ fever outbreaks have not been reported (Hryniewiecki et al., 2001). It is not clear whether this was the result of the low pathogenicity of circulating strains or low detection of human cases and notification of the disease. In the newest study, the presence of C. burnetii DNA has been shown in heart valves and in the myocardium of malfunctioning human hearts. The obtained results indicate that among patients with cardiac diseases, infections caused by C. burnetii could occur and should be obligatorily tested (Mączka et al., 2011).

\section{Literatura}

Amano K. and J.C. Williams. 1984. Chemical and immunological characterization of lipopolysaccharides from phase I and phase II Coxiella burnetii. J. Bacteriol. 160: 994-1002.

Amano K, J.C. Williams, T.F. McCaul and M.G. Peacock. 1984. Biochemical and immunological properties of Coxiella burnetii cell wall and peptidoglycan-protein complex fractions. J. Bacteriol. 160: 982-988.

Amitai Z., M. Bromberg, M. Bernstein, D. Raveh, A. Keysary, D. David, S. Pitlik, D. Swerdlow, R. Massung, S. Rzotkiewicz, O. Halutz and T. Shohat. 2010. A large Q fever outbreak in an urban school in central Israel. Clin. Infect. Dis. 50: 1433-1438.

Anusz Z., H. Ciecierski, J. Knap, Z. Piesiak, A. Platt-Samoraj, J. Siemionek, W. Szweda, M. Szymański, J. Łęcki and E. Kowalska. Q fever in Poland in the years 1952-1995. Rickettsiae and rickettsial diseases Proceedings of the $\mathrm{V}^{\text {th }}$ International Symposium, 1-6.09. 1996, Bratislava.

Anusz Z., J. Knap, J. Ziemka, Z. Piesiak, K. Borko, H. Ciecierski, D. Kruszewska, Z. Lewińska, E. Mikołajczyk and W. Rumin. 1986. Two foci of Q fever in humans, sheep and cattle in the Olsztyn province. Przegl. Epidemiol. 40: 349-361.

Anusz Z., J. Rehacek, J. Knap, H. Krauss, H. Ciecierski, A. PlattSamoraj, W. Wodecki and P. Lewicki. 1991. Sytuacja epizootiologiczno-epidemiologiczna gorączki Q u bydła i ludzi w regionie Żuław. Acta. Acad. Agricult. Tech. Olst. Vet. 20: 35-45.

Anusz Z., E. Walkowiak, J. Krupa, D. Kruszewska, W. Rumin and H. Ciecierski. Occurence of Coxiella burnetii antibodies in bisons (Bison bonasus) from Bialowieski Primeval Forest and in cattle and sheep from villages around it. Proceedings of the 37 Annual Meeting of the European Association for Animal Production; 1991 Sep 1-6; Budapest, Hungary: Summaries. p. 538.

Anusz Z. Q fever in humans and animals. Olsztyn: WART; 1995. Arricau-Bouvery N., Y. Hauck, A. Bejaoui, D. Frangoulidis, C.C. Bodier, A. Souriau, H. Meyer, H. Neubauer, A. Rodolakis and G. Vergnaud. 2006. Molecular characterization of Coxiella burnetii isolates by infrequent restriction site-PCR and MLVA typing. BMC Microbiol. 6: 38 .

Avakyan A.A., V.L. Popov, S.M. Chebanov, A.A. Shatkin, V.E. Sidorov and R.I. Kudelina. 1983. Comparison of the ultrastructure of small dense forms of chlamydiae and Coxiella burnetii. Acta Virol. 2: 168-172.

Ayres J.G., E.G. Smith and N. Flint. 1996. Protracted fatigue and debility after acute Q fever. Lancet 347: 978.
Babudieri B. 1959. Q fever: A zoonosis. Adv. Vet. Sci. 5: 81-154. Baca O.G. and M.R. Yeaman. 1991. Antibiotic susceptibilities and possible resistance mechanisms of several Coxiella burnetii isolates. (W:) J. Kazar and D. Raoult: Rickettsiae and Rickettsial Diseases. Bratislava, pp.: 700-713.

Barandika J.F., A. Hurtado, C. García-Esteban, H. Gil, R. Escudero, M. Barral, I. Jado, R.A. Juste, P. Anda and A.L. GarcíaPérez. 2007. Tick-borne zoonotic bacteria in wild and domestic small mammals in northern Spain. Appl. Environ. Microbiol. 73: 6166-6171.

Bautista-Hernández V., F. Gutierrez, V.G. Ray, J.M. Arribas, J. García-Puente, N. Casinello and R. Arcas. 2004. Constrictive pericarditis due to Coxiella burnetii. Ann. Thorac. Surg. 1: 326-328. Beare P.A., J.E. Samuel, D. Howe, K. Virtaneva, S.F. Porcella and R.A. Heinzen. 2006. Genetic diversity of the Q fever agent, Coxiella burnetii, assessed by microarray-based whole-genome comparisons. J. Bacteriol. 188: 2309-2324.

Bernit E., J. Pouget, F. Janbon, H. Dutronc, P. Martinez, P. Brouqui and D. Raoult. 2002. Neurological involvement in acute Q fever: a report of 29 cases and review of the literature. Arch. Intern. Med. 162: 693-700

Botelho-Nevers E., P.E. Fournier, H. Richet, F. Fenollar, H. Lepidi, C. Foucault, A. Branchereau, P. Piquet, M. Maurin and D. Raoult. 2007. Coxiella burnetii infection of aortic aneurysms or vascular grafts: report of 30 new cases and evaluation of outcome. Eur. J. Clin. Microbiol. Infect. Dis. 26: 635-640.

Burnet F.M. and M. Freeman. 1937. Experimental studies on the virus of "Q" fever. Med. J. Aust. 2: 299.

Burnet F.M. and M. Freeman. 1938. The rickettsia of Q fever: further experimental studies. Med. J. Aust. 1: 296.

Carcopino X., D. Raoult, F. Bretelle, L. Boubli and A. Stein. 2009. Q Fever during pregnancy: a cause of poor fetal and maternal outcome. Ann. N. Y. Acad. Sci. 1166: 79-89.

Carrieri, M.P., H. Tissot-Dupont, D. Rey, P. Brousse, H. Renard, Y. Obadia and D. Raoult. 2002. Investigation of a slaughterhouserelated outbreak of Q fever in the French Alps. Eur. J. Clin. Microbiol. Infect. Dis. 21: 17-21.

Chevalier P., F. Vandenesch, P. Brouqui, G. Kirkorian, A. Tabib, J. Etienne, D. Raoult, R. Loire and P. Touboul. 1997. Fulminant myocardial failure in a previously healthy young man. Circulation. 95: 1654-1657.

Chmielewski T., K. Sidi-Boumedine, V. Duquesne, E. Podsiadly, R. Thiéry and S. Tylewska-Wierzbanowska. 2009. Molecular epidemiology of Q fever in Poland. Pol. J. Microbiol. 58: 9-13

Chmielewski T. and S. Tylewska-Wierzbanowska. 2011. Inhibition of fibroblast apoptosis by Borrelia afzelii, Coxiella burnetii and Bartonella henselae. Pol. J. Microbiol. 60: 269-272.

Chrzanowski J., I. Kularska, R. Stempień and L. Wojciechowski. 1960. Badania serologiczne w kierunku gorączki Q wśród pracowników przemysłu wełnianego. Przeg. Epid. 4: 411-416.

Coleman S.A., E.R. Fischer, D.C. Cockrell, D.E. Voth, D. Howe, D.J. Mead, J.E. Samuel and R.A. Heinzen. 2007. Proteome and antigen profiling of Coxiella burnetii developmental forms. Infect. Immun. 75: 290-298.

Coleman S.A., E.R. Fischer, D. Howe, D.J. Mead and R.A. Heinzen. 2004. Temporal analysis of Coxiella burnetii morphological differentiation. J. Bacteriol. 186: 7344-7352.

Cottalorda J., J.L. Jouve, G. Bollini, P. Touzet, A. Poujol, F. Kelberine and Raoult D. 1995. Osteoarticular infection due to Coxiella burnetii in children. J. Pediatr. Orthop. B. 4: 219-221.

Cox H.R. 1941. Cultivation of rickettsiae of the rocky mountain spotted fever, typhus and Q fever groups in the embryonic tissues of developing chicks. Science. 94(2444): 399-403.

Czopowicz M., J. Kaba, O. Szaluś-Jordanow, M. Nowicki, L. Witkowski, D. Nowicka and T. Frymus. 2010. Prevalence of 
antibodies against Chlamydophila abortus and Coxiella burnetii in goat herds in Poland. Pol. J. Vet. Sci. 13: 175-179.

Denison A.M., R.F. Massung and H.A. Thompson. 2007. Analysis of the O-antigen biosynthesis regions of phase II isolates of Coxiella burnetii. FEMS Microbiol. Lett. 267: 102-107.

Derrick E.H. 1937. Q fever, a new fever entity: clinical features, diagnosis and laboratory investigation. Med. J. Aust. 2: 281.

Dorko E., K. Rimarova, E. Pilipcinec and M. Travnicek. 2009. Prevalence of Coxiella burnetii antibodies in wild ruminants in Kavecany zoo, Kosice, eastern Slovakia. Ann. Agric. Environ. Med. 16: $321-324$

Dupuis G., J. Petite, O. Péter and M. Vouilloz. 1987. An important outbreak of human Q fever in a Swiss Alpine valley. Int. J. Epidemiol. 16: 282-287.

Ellis M.E., C.C. Smith and Moffat M.A. 1983. Chronic and fatal Q-fever infection: a review of 16 patients seen in North-East Scotland (1967-1980). Q.J. Med. 52: 54-66.

Enserink M. 2010. Infectious diseases. Questions abound in Q-fever explosion in the Netherlands. Science 327: 266-267

Fenollar F., F. Thuny, F. Xeridat, H. Lepidi and D. Raoult. 2006. Endocarditis after acute $\mathrm{Q}$ fever in patients with previously undiagnosed valvulopathies. Clin. Infect. Dis. 42: 818-821.

Fishbein D.B. and D. Raoult. 1992. A cluster of Coxiella burnetii infections associated with exposure to vaccinated goats and their unpasteurized dairy products. Am. J. Trop. Med. Hyg. 47: 35-40.

Fournier P.E., J. Etienne, J.R. Harle, G. Habib and D. Raoult. 2001. Myocarditis, a rare but severe manifestation of $\mathrm{Q}$ fever: report of 8 cases and review of the literature. Clin. Infect. Dis. 32: 1440-1447. Gawron H. and K. Wagner. 1962. A focus of Q-fever in Gdańsk in 1962. Przegl. Epid. 1: 87-89.

Gikas A., D.P. Kofteridis, A. Manios, J. Pediaditis and Y. Tselentis. 2001. Newer macrolides as empiric treatment for acute Q fever infection. Antimicrob. Agents Chemother. 45: 3644-3646.

Gilsdorf A., C. Kroh, S. Grimm, E. Jensen, C. Wagner-Wiening and K. Alpers. 2008. Large Q fever outbreak due to sheep farming near residential areas, Germany, 2005. Epidemiol. Infect. 136: 1084-1087.

Gimenez G., C. Bertelli, C. Moliner, C. Robert, D. Raoult, P.E. Fournier and G. Greub. 2011. Insight into cross-talk between intra-amoebal pathogens. BMC Genomics. 2; 12: 542.

Glazunowa O., V. Roux, O. Freylikman, Z. Sekeyova, G. Fournous, J. Tyczka, N. Tokarevich, E. Kovacava, T.J. Marrie and D. Raoult. 2005. Coxiella burnetii genotyping. Emerg. Inf. Dis. 11: 1211-1217. Gouriet F., F. Fenollar, J.Y. Patrice, M. Drancourt and D. Raoult. 2005. Use of shell-vial cell culture assay for isolation of bacteria from clinical specimens: 13 years of experience. J. Clin. Microbiol. 43: 4993-5002.

Greub G. and D. Raoult. 2004. Microorganisms resistant to freeliving amoebae. Clin. Microbiol. Rev. 17: 413-433.

Hatchette T.F., R.C. Hudson, W.F. Schlech, N.A. Campbell, J.E. Hatchette, S. Ratnam, D. Raoult, C. Donovan and T.J. Marrie. 2001. Goat-associated Q fever: a new disease in Newfoundland. Emerg. Infect. Dis. 7: 413-419.

Hendrix L.R., J.E. Samuel and L.P. Mallavia. 1991. Differentiation of Coxiella burnetii isolates by analysis of restriction-endonuclease-digested DNA separated by SDS-PAGE. J. Gen. Microbiol. 137: 269-276

Honstettre A., E. Ghigo, A. Moynault, C. Capo, R. Toman, S. Akira, O. Takeuchi, H. Lepidi, D. Raoult and J.L. Mege. 2004. Lipopolysaccharide from Coxiella burnetii is involved in bacterial phagocytosis, filamentous actin reorganization, and inflammatory responses through Toll-like receptor 4. J. Immunol. 172: 3695-3703 Hoover T.A., D.W. Culp, M.H. Vodkin, J.C. Williams and H.A. Thompson. 2002. Chromosomal DNA deletions explain phenotypic characteristics of two antigenic variants, phase II and
RSA 514 (crazy), of the Coxiella burnetii Nine Mile strain. Infect Immun. 70: 6726-6733

Hryniewiecki T., S. Tylewska-Wierzbanowska and I. RawczyńskaEnglert. 2001. Attempt of estimation of Q fever endocarditis frequency in Poland. Przegl. Lek. 58: 759-761

Ioannou I., D. Chochlakis, N. Kasinis, P. Anayiotos, A. Lyssandrou, B. Papadopoulos, Y. Tselentis and A. Psaroulaki. 2009. Carriage of Rickettsia spp., Coxiella burnetii and Anaplasma spp. by endemic and migratory wild birds and their ectoparasites in Cyprus. Clin. Microbiol. Infect. 15 Suppl 2: 158-160.

Jäger C., S. Lautenschläger, H. Willems and G. Baljer. 2002. Coxiella burnetii plasmid types QpDG and QpH1 are closely related and likely identical. Vet. Microbiol. 89: 161-166

Jäger C., H. Willems, D. Thiele and G. Baljer. 1998. Molecular characterization of Coxiella burnetii isolates. Epidemiol. Infect. 120(2): 157-164

Janigan D.T. and T.J. Marrie. 1983. An inflammatory pseudotumor of the lung in Q fever pneumonia. N. Engl. J. Med. 308: 86-88.

Karakousis P., M. Trucksis and S. Dumler. 2006. Chronic Q fever in the United States. J. Clin. Microbiol. 44: 2283-2287.

King L.A., L. Goirand, H. Tissot-Dupont, B. Giunta, C. Giraud, C. Colardelle, V. Duquesne, E. Rousset, M. Aubert, R. Thiéry, L. Calatayud, G. Daurat, L. Hocqueloux, V. Cicchelero, F. Golliot, and H. de Valk. 2011. Outbreak of Q fever, Florac, Southern France, Spring 2007. Vector Borne Zoonotic Dis. 11: 341-347.

Kishimoto R.A., R.W. Stockman and C.L. Redmond. 1979. Q fever: diagnosis, therapy, and immunoprophylaxis. Mil. Med. 144: 183-187.

Kofteridis D.P., E.E. Mazokopakis, Y. Tselentis and A. Gikas. 2004. Neurological complications of acute Q fever infection. Eur. J. Epidemiol. 19: 1051-1054.

Kruszewska D., K. Lembowicz and S. Tylewska-Wierzbanowska. 1996. Possible sexual transmission of Q fever among humans. Clin. Infect. Dis. 22: 1087-1088.

Kruszewska D. and S. Tylewska-Wierzbanowska. 1991. Influence of Coxiella burnetii infection of male mice on their offspring. Acta Virol. 35: 79-82.

Kruszewska D. and S. Tylewska-Wierzbanowska. 1997. Isolation of Coxiella burnetii from bull semen. Res. Vet. Sci. 62: 299-300.

Kruszewska D. and S.K. Tylewska-Wierzbanowska. 1993. Coxiella burnetii penetration into the reproductive system of male mice, promoting sexual transmission of infection. Infect. Immun. 61: 4188-4195.

La Scola B. and D. Raoult. 2001. Survival of Coxiella burnetii within free-living amoeba Acanthamoeba castellanii. Clin. Microbiol. Infect. 75-9.

Levy P.Y., P. Carrieri and D. Raoult. 1999 Coxiella burnetii pericarditis: report of 15 cases and review. Clin. Infect. Dis. 29(2): 393-397. Lührmann A. and C.R. Roy. 2007. Coxiella burnetii inhibits activation of host cell apoptosis through a mechanism that involves preventing cytochrome $\mathrm{c}$ release from mitochondria. Infect. Immun. 75: 5282-5289.

Lutynski R. 1956. First focus of Q-fever on the territory of Poland. Przegl. Lek. 12: 187-188.

Lyytikäinen O., T. Ziese, B. Schwartländer, P. Matzdorff, C. Kuhnhen, C. Jäger and L. Petersen. 1998. An outbreak of sheepassociated Q fever in a rural community in Germany. Eur J Epidemiol. 14: 193-199.

Mayer H., J. Radziejewska-Lebrecht and S. Schramek. 1988. Chemical and immunochemical studies on lipopolysaccharides of Coxiella burnetii phase I and phase II. Adv. Exp. Med. Biol. 228: 577-591.

Mączka I. T. Chmielewski, E. Walczak, J. Różański, G. Religa, and S. Tylewska-Wierzbanowska. 2011. Tick-borne infections as a cause of heart transplantation. Pol. J. Microbiol. 60: 341-343. 
Mallavia L.P. 1991. Genetics of rickettsiae. Eur. J. Epidemiol. 7: 213-221.

Maltezou H.C., J. Constantopoulou, C. Kallergi, V. Vlahou, D. Georgakopoulos, D.A. Kafetzis and D. Raoult. 2004. Q fever in children in Greece. Am. J. Trop. Med. Hyg. 70: 540-544.

Marrie T.J., A. MacDonald, H. Durant, L. Yates and L. McCormick. 1988. An outbreak of Q fever probably due to contact with a parturient cat. Chest. 93: 98-103.

Marrie T.J., W.F. Schlech, J.C. Williams and L. Yates. 1986. Q fever pneumonia associated with exposure to wild rabbits. Lancet. 1: 427-429.

Marrie T.J., A. Stein, D. Janigan and D. Raoult. 1996. Route of infection determines the clinical manifestations of acute $\mathrm{Q}$ fever. J. Infect. Dis. 173: 484-487.

Maurin M. and D. Raoult. 1999. Q fever. Clin. Microbiol. Rev. 4: 518-553.

Maurin M. and D. Raoult. Antimicrobial therapy of rickettsial diseases. (eds.) D. Raoult and P. Brouqui. Rickettsiae and Rickettsial Diseases at the Turn of the Thrid Millenium 1999, p. 330-342.

McCaul T.F., A.J. Dare, J.P. Gannon and A.J. Galbraith. 1994. In vivo endogenous spore formation by Coxiella burnetii in $\mathrm{Q}$ fever endocarditis. J. Clin. Pathol. 47: 978-981.

McCaul T.F. and J.C. Williams. 1981. Developmental cycle of Coxiella burnetii: structure and morphogenesis of vegetative and sporogenic differentiations. J. Bacteriol. 147: 1063-1076.

McQuiston J.H. and J.E. Childs. 2002. Q fever in humans and animals in the United States. Vector Borne Zoonotic Dis. 2: 179-191

Meiklejohn G., L.G. Reimer, P.S. Graves and C. Helmick. 1981. Cryptic epidemic of Q fever in a medical school. J. Infect. Dis. 144: 107-113.

Mikolajczyk E., Z. Lewińska, R. Lojewska, W. Rumin and D. Kruszewska. 1986. Serologic reactions in humans during the outbreak of Q fever. Przeg. Epid. 40: 342-348.

Nguyen S.V. and K. Hirai. 1999. Differentiation of Coxiella burnetii isolates by sequence determination and PCR-restriction fragment length polymorphism analysis of isocitrate dehydrogenase gene. FEMS Microbiol. Lett. 180: 249-254

Ong C., O. Ahmad, S. Senanayake, G. Buirski and C. Lueck. 2010. Optic neuritis associated with Q fever: case report and literature review. Int. J. Infect. Dis. 145: 269-273.

Ormsbee R.A., M.G. Peacock, R. Gerloff, G. Tallent and D. Wike. 1978. Limits of rickettsial infectivity. Infect. Immun. 19: 239-245.

Ortolá P.R., F.G. Peñalba, C.J. Ruiz and M.A. Angulo. 1992. Coxiella burnetii osteoarthritis. Rev. Clin. Esp. 191: 25-26

Panaiotov S., M. Ciccozzi, N. Brankova, V. Levterova, M. MitovaTiholova, M. Amicosante, G. Rezza and T. Kantardjiev. 2009. An outbreak of Q fever in Bulgaria. Ann. Ist. Super. Sanita. 45: 83-86.

Porten K., J. Rissland, A. Tigges, S. Broll, W. Hopp, M. Lunemann, U. van Treeck, P. Kimmig, S.O. Brockmann, C. Wagner-Wiening, W. Hellenbrand and U. Buchholz. 2006. A super-spreading ewe infects hundreds with Q fever at a farmers' market in Germany. BMC Infect. Dis. 6: 147.

Raoult D., G. Bollini and H. Gallais. 1989. Osteoarticular infection due to Coxiella burnetii. J. Infect. Dis. 159: 1159-1160.

Raoult D., F. Fenollar and A. Stein. 2002. Q fever during pregnancy: diagnosis, treatment, and follow-up. Arch. Intern. Med. 162: 701-704.

Raoult D., P. Houpikian, H. Tissot Dupont, J.M. Riss, J. ArditiDjiane and P. Brouqui. 1999. Treatment of Q fever endocarditis: comparison of 2 regimens containing doxycycline and ofloxacin or hydroxychloroquine. Arch. Intern. Med. 159: 167-173

Raoult D. Antibiotic treatment of rickettsiosis, recent advances and current concepts. In: Kazar J., Raoult D. Rickettsiae and rickettsial diseases. Bratislava 1991, 652-662.
Raoult D. 1993. Treatment of Q fever. Antimicrob. Agents. Chemother. 37: 1733-1736.

Rehacek J. and Tarasevich I.V. Q fever. In: Acari-borne rickettsiae \& rickettsioses in Eurasia. Veda Publishing House of the Slovak Academy of Sciences. Bratislava 1988.

Rowbotham T.J. 1983. Isolation of Legionella pneumophila from clinical specimens via amoebae, and the interaction of those and other isolates with amoebae. J. Clin. Pathol. 36: 978-986.

Ruiz-Fons F., O. Rodríguez, A. Torina, V. Naranjo, C. Gortázar, and J. de la Fuente. 2008. Prevalence of Coxiella burnetti infection in wild and farmed ungulates. Vet. Microbiol. 126: 282-286.

Salmon M.M., B. Howells, E.J. Glencross, A.D. Evans and S.R. Palmer. 1982. Q fever in an urban area. Lancet 1: 1002-1004 Schramek S., J. Radziejewska-Lebrecht and H. Mayer. 1985. 3-C-branched aldoses in lipopolysaccharide of phase I Coxiella burnetii and their role as immunodominant factors. Eur. J. Biochem. 148(3): 455-461.

Scott G.H. and J.C. Williams. 1990. Susceptibility of Coxiella burnetii to chemical disinfectants. Ann. N.Y. Acad. Sci. 590: 291-296. Segal G., M. Feldman and T. Zusman. 2005. The Icm/Dot type-IV secretion systems of Legionella pneumophila and Coxiella burnetii. FEMS Microbiol. Rev. 29: 65-81.

Serbezov V.S., J. Kazár, V. Novkirishki, N. Gatcheva, E. Kovácová and V. Voynova. 1999. Q fever in Bulgaria and Slovakia. Emerg. Infect. Dis. 5: 388-394.

Seshadri R., I.T. Paulsen, J.A. Eisen, T.D. Read, K.E. Nelson, W.C. Nelson, N.L. Ward, H. Tettelin, T.M. Davidsen, M.J. Beanan, R.T. Deboy, S.C. Daugherty, L.M. Brinkac, R. Madupu, R.J. Dodson, H.M. Khouri, K.H. Lee, H.A. Carty, D. Scanlan, R.A. Heinzen, H.A. Thompson, J.E. Samuel, C.M. Fraser and J.F. Heidelberg. 2003. Complete genome sequence of the Q-fever pathogen Coxiella burnetii. Proc. Natl. Acad. Sci. USA 100: 5455-5460. Sessa C., L. Vokrri, P. Porcu, M. Maurin, J.P. Stahl and J.L. Magne. 2005. Abdominal aortic aneurysm and Coxiella burnetii infection: report of three cases and review of the literature. J. Vasc. Surg. 42: 153-158.

Slabá K., A. Hussein, P. Palkovic, V. Horváth and R. Toman. 2003. Studies on the immunological role of virenose and dihydrohydroxystreptose present in the Coxiella burnetii phase I lipopolysaccharide. Ann. N.Y. Acad. Sci. 990: 505-509

Speelman P. 2010. The largest Q fever outbreak ever reported. Neth. J. Med. 68: 380-381.

Spelman DW. 1982. Q fever: a study of 111 consecutive cases. Med. J. Aust. 1: 547-553.

Spicer A.J., M.G. Peacock and J.C. Williams. 1981. Effectiveness of several antibiotics in suppressing chick embryo lethality during experimental infections by Coxiella burnetii, Rickettsia typhi and R. rickettsii. (In:) W. Burgdorfer, R. 1. Anacker Rickettsiae and rickettsial Diseases. Academic Press, New York, 375-383.

Stein A. and D. Raoult. 1999. Pigeon pneumonia in provence: a bird-borne Q fever outbreak. Clin. Infect. Dis. 29: 617-620.

Stein A. and D. Raoult. 1998. Q fever during pregnancy: a public health problem in southern France. Clin Infect Dis. 27: 592-596

Stein A., N.A. Saunders, A.G. Taylor and D. Raoult. 1993. Phylogenic homogeneity of Coxiella burnetii strains as determinated by $16 \mathrm{~S}$ ribosomal RNA sequencing. FEMS Microbiol. Lett. 113: 339-344.

Stempień R., Z. Deroń, T. Górski, M. Libich, A. Vogel and M. Dadak. 1985. Imported leather raw materials as a cause of $Q$ fever. Przegl. Epidemiol. 39: 218-223.

Tilburg J.J., J.W. Rossen, E.J. van Hannen, W.J. Melchers, M.H. Hermans, J. van de Bovenkamp, H.J. Roest, A. de Bruin, M.H. Nabuurs-Franssen, A.M. Horrevorts and C.H. Klaassen. 2012. Genotypic diversity of Coxiella burnetii in the 2007-2010 
Q fever outbreak episodes in The Netherlands. J. Clin. Microbiol. 50: 1076-1078.

Tissot Dupont H., D. Raoult, P. Brouqui, F. Janbon, D. Peyramond, P.J. Weiller, C. Chicheportiche, M. Nezri and R. Poirier. 1992. Epidemiologic features and clinical presentation of acute Q fever in hospitalized patients: 323 French cases. Am. J. Med. 93: 427-434. Tissot-Dupont H., M.A. Amadei, M. Nezri and D. Raoult. 2004 Wind in November, Q fever in December. Emerg. Infect. Dis. 10: 1264-1269.

Tissot-Dupont H., S. Torres, M. Nezri and D. Raoult. 1999. Hyperendemic focus of $\mathrm{Q}$ fever related to sheep and wind. Am. J. Epidemiol. 150: 67-74.

Tobin M.J., Cahill N., Gearty G., Mauer B., Blake S., Daly K. and R. Hone. 1982. Q-fever endocarditis. Am. J. Med. 72: 369-400. Tylewska-Wierzbanowska S., D. Kruszewska and T. Chmielewski. 1996. Epidemics of Q-fever in Poland in 1992-1994. Ann. Acad. Med. Bial. 1: 123-128.

Tylewska-Wierzbanowska S., H. Lewkowicz and M. Wesołowska. 1993. Coxiella burnetii infections ( $Q$ fever) in animals and humans in Poznan and Leszno districts detected by serodiagnosis. Przegl. Epidemiol. 47: 399-404.

Tylewska-Wierzbanowska S., W. Rumin, H. Lewkowicz and S. Sikorski. 1991. Epidemic of Q-fever in Leszno district in Poland. Eur. J. Epidemiol. 3: 307-309.

Valková D. and J. Kazár. 1995. A new plasmid (QpDV) common to Coxiella burnetii isolates associated with acute and chronic $\mathrm{Q}$ fever. FEMS Microbiol. Lett. 125: 275-280.

Varma M.P., A.A. Adgey and J.H. Connoly. 1980. Chronic Q-fever endocarditis. Br. Heart J. 43, 695-699.

Vogiatzis I., G. Dimoglou and V. Sachpekidis. 2008. Q fever myocarditis. Hippokratia12: 46-49
Voth D.E. and R.A. Heinzen. 2009. Sustained activation of Akt and Erk1/2 is required for Coxiella burnetii antiapoptotic activity. Infect. Immun. 77: 205-213.

Voth D.E., D. Howe and R.A. Heinzen. 2007. Coxiella burnetii inhibits apoptosis in human THP-1 cells and monkey primary alveolar macrophages. Infect. Immun. 75: 4263-4271.

Vranakis I., P.J. De Bock, A. Papadioti, Y. Tselentis, K. Gevaert, G. Tsiotis and A. Psaroulaki. 2011. Identification of potentially involved proteins in levofloxacin resistance mechanisms in Coxiella burnetii. J. Proteome Res. 10: 756-762.

Vranakis I., V. Sandalakis, D. Chochlakis, Y. Tselentis and A. Psaroulaki. 2010. DNA gyrase and topoisomerase IV mutations in an in vitro fluoroquinolone-resistant Coxiella burnetii strain. Microb. Drug Resist. 16: 111-117.

Weisburg W.G., M.E. Dobson, J.E. Samuel, G.A. Dasch, L.P. Mallavia, O. Baca, L. Mandelco, J.E. Sechrest, E. Weiss and C.R. Woese. 1989. Phylogenetic diversity of the Rickettsiae. J. Bacteriol. 171: 4202-4206.

Westlake P., L.M. Price, M. Russell and J.K. Kelly. 1987. The pathology of Q fever hepatitis. A case diagnosed by liver biopsy. J. Clin. Gastroenterol. 9: 357-363.

Willems H., D. Thiele and H. Krauss. 1993. Plasmid differentiation and detection of Coxiella burnetii in clinical samples. Eur. J. Epidemiol. 9: 411-418.

Yadav M.P. and M.S. Sethi. 1979. Poikilotherms as reservoirs of Q-fever (Coxiella burnetii) in Uttar Pradesh. J. Wildl. Dis. 15: 15-17. Yeaman M.R. and O.G. Baca. 1990. Unexpected antibiotic susceptibility of a chronic isolate of Coxiella burnetii. Ann. N. Y. Acad. Sci. 590: 297-305.

Yebra M., M. Marazuela, F. Albarrán and A. Moreno. 1988. Chronic Q fever hepatitis. Rev. Infect. Dis. 10: 1229-1230. 